\title{
What is Offshoring Management Capability and How Do Organizations Develop It? A Study of Dutch IT Service Providers
}

\author{
Mashiho Mihalache ${ }^{1}$. Oli R. Mihalache ${ }^{2}$
}

Received: 9 August 2018 / Revised: 17 May 2019 / Accepted: 11 November 2019 /

Published online: 5 December 2019

(c) The Author(s) 2019

\begin{abstract}
This study develops a capability perspective of offshoring. While previous research shows that experience affects future offshoring decisions, we still lack an understanding of what offshoring management capability is and how organizations develop it. Using data on five Dutch IT service providers, we find that offshoring management capability is multidimensional as it comprises four dimensions: coordination competency, relationship development, relationship design, and organizational identification. Furthermore, we uncover the process through which organizations can actively develop an offshoring management capability. We find that there are four elements in this learning loop: an offshoring growth mentality, adaptive monitoring of offshoring performance, offshoring reflexivity, and mechanisms for storing and disseminating offshoring best practice. Therefore, our capability perspective of offshoring provides a comprehensive conceptualization of offshoring management capability as a multidimensional construct and uncovers the process through which organizations develop it.
\end{abstract}

Keywords Offshoring · Global sourcing · Management capability · Organizational learning · Qualitative research

\section{Introduction}

Offshoring refers to the relocation of business processes to foreign countries to support current business operations (Contractor et al. 2010; Levy 2005; Mihalache et al. 2012). Offshoring owes its popularity to the fact that it allows organizations to access the specific relative advantages of foreign countries (Kedia and Mukherjee

Mashiho Mihalache

m.mihalache@uva.nl

1 Amsterdam Business School, University of Amsterdam, Amsterdam, The Netherlands

2 Vrije Universiteit Amsterdam, Amsterdam, The Netherlands 
2009), such as lower factor costs (Larsen et al. 2013), large pools of qualified workers (Lewin et al. 2009), and specialized knowledge (Mihalache et al. 2012; Rosenbusch et al. 2019; Steinberg et al. 2017). In order to achieve these benefits, organizations need to overcome challenges such as coordinating operations that are culturally and geographically distant (for a review, see Mihalache and Mihalache 2016). While many organizations struggle to overcome these challenges and some, discouraged by early disappointing results, even decide to bring operations back home (Kinkel 2014), others can use their initial experiences to develop capabilities for managing offshoring (Haleem et al. 2018). So, what does an offshoring management capability comprise and how can organizations develop it?

While previous research hints at the existence of an offshoring management capability (e.g., Bhalla et al. 2008; Doh 2005; Levy 2005), it does not provide a comprehensive analysis of what this comprises. Previous studies suggest capabilities such as cultural intelligence (Ang and Inkpen 2008) or the ability to collaborate with offshore parties (King and Torkzadeh 2008; Manning et al. 2008; Mukherjee et al. 2017), but these address only particular elements of what is necessary to manage offshore activities. To capture the complexity of offshoring we need a comprehensive understanding of what an offshoring management capability comprises.

Similarly, we do not fully understand the process through which organizations leverage their experience to develop this capability. Previous research finds that offshoring experience is important for future decision-making as it reduces errors in cost estimation (Larsen et al. 2013), lowers risk perceptions in areas such as loss of intellectual property (Lewin and Peeters 2006), and supports venturing to riskier locations (Hahn et al. 2009). Also, previous findings that organizations start to offshore more complex tasks as they gain more experience of offshoring (e.g., Carmel and Agarwal 2002; Lewin and Peeters 2006) suggest that organizations can learn how to offshore. However, there are mixed results when it comes to how experience affects the success of offshoring projects; some studies find that experience is associated with achieving offshoring goals (Haleem et al. 2018), while others fail to find any link (Hutzschenreuter et al. 2011). This suggests that leveraging experience to develop offshoring management capabilities is not straightforward and the learning process still needs to be better understood. That is, previous research assumes that organizations learn how to manage offshoring activities, but it does not investigate the learning process explicitly. Recognizing this lacuna in our understanding, identified through an extensive systematic review of more than 180 offshoring studies, Mihalache and Mihalache (2016, p. 1129) ask "what are the mechanisms through which firms learn from experience?".

This study advances offshoring research by developing a capability perspective of offshoring. It complements previous studies that have alluded to the existence and importance of offshoring capability (Bhalla et al. 2008; Carmel and Agarwal 2002; Levy 2005) as it provides a more comprehensive understanding of offshoring management capability. Specifically, we find that the offshoring management capability is multidimensional, consisting of coordination competency, relationship development, relationship design, and organizational identification. Furthermore, our study uncovers the process through which organizations can leverage their offshoring experience to develop an offshoring management capability. Organizations are often 
engaged in a diverse range of offshoring activities (e.g., Lewin and Peeters 2006; Lin et al. 2017), so there is potential for them to learn how to manage offshoring. We find that developing offshoring management capability is a deliberate activity; it requires organizations to cultivate an offshoring growth mentality and to adopt mechanisms that enable them to adjust their monitoring of offshoring performance, engage in reflexivity, and store and share best practice in offshoring. By uncovering the underlying process through which organizations learn how to manage offshoring, we build on organizational learning theory (Levitt and March 1988), to advance previous studies that show the importance of offshoring experience for offshoring decision-making (e.g., Hahn et al. 2009; Lewin and Peeters 2006) and those that suggest the existence of organizational learning in offshoring (e.g., Asmussen et al. 2016; Carmel and Agarwal 2002). Our study also complements previous research showing that organizations learn how to offshore in an impromptu manner (Parida et al. 2013), since we find that organizations can employ structured learning processes in order to develop an offshoring management capability.

The remainder of the study is organized as follows. First, we present building blocks from the literature that enable us to take a capability perspective of offshoring and identify gaps in our knowledge. We then present our methodology and the cases (Dutch IT service providers) used to develop theory. Next, we present our offshoring management capability model and the case evidence. We conclude the study by discussing our findings' theoretical contributions to existing offshoring research and their practical implications.

\section{Literature Review: Towards a Capability Perspective of Offshoring}

Increased globalization over the last few decades has changed how firms organize their value chain (Liesch et al. 2012). Offshoring refers to firms' moving business processes to foreign locations with particular factor advantages (Mihalache and Mihalache 2016). The offshored activities can be undertaken either within the boundaries of the firm (i.e., captive offshoring) or by a contracted party (i.e., offshore outsourcing) (Nunn and Trefler 2013; Thakur-Wernz and Bruyaka 2017). Firms initially attempted to leverage costs differentials, particularly with regard to developing countries, by offshoring manufacturing activities (Lewin and Peeters 2006). Advances in information technology then made it possible to separate service work from the service delivery location, as technology facilitates low-cost communication and international data transfer (Metters and Verma 2008; Pisani and Ricart 2016). This stimulated a new wave of offshoring, with firms increasingly moving abroad business processes of various degrees of complexity (Boehe 2010; Doh et al. 2009; Jain et al. 2008; Jha et al. 2018; Musteen et al. 2017).

Offshoring is attractive because it can provide access to a large pool of qualified workers (Lewin et al. 2009), lower wages (Larsen et al. 2013; Lieberman 2004; Youngdahl et al. 2008), or specialized knowledge (Lehrer and Asakawa 2003; Mihalache et al. 2012; Nieto and Rodríguez 2011; Pisani and Ricart 2018). However, despite the increase in offshoring, such initiatives vary considerably in their degree of success. This is because offshoring involves various challenges that firms 
need to overcome if they are to enjoy the promised benefits. These challenges are associated with managing operations at geographically distant locations and include coordination and control (Ravichandran and Ahmed 1993) across cultural and institutional distance (Ashforth and Mael 1989; Beugre and Acar 2008; Uzzi 1997). These difficulties are sometimes called the "invisible" (Stringfellow, Teagarden and Nie 2008) or 'hidden' (Apte and Mason 1995) costs of offshoring, as many organizations initially underestimate or even ignore them. Interestingly, there are considerable differences in how organizations respond to these challenges; while some decide to stop offshoring and backshore (e.g., Kinkel 2014), others are able to use these early experiences to learn how to manage offshoring initiatives (e.g., Haleem et al. 2018). In other words, some organizations can develop capabilities for managing offshoring, while others cannot.

Organizational capabilities refer to how organizations manipulate resources, i.e., the factors an organization owns such as human resources, in order to achieve their desired goals (Amit and Schoemaker 1993). In this study, we focus specifically on capabilities required to manage offshoring activities and on learning "how to" offshore. This comes in contrast with a considerable body of previous offshoring research that uses the terms "capability" and "learning" to refer to the acquisition of technology, knowledge, or skills from abroad (see for e.g., Jensen 2009). That is, our focus is on the learning required for managing offshoring rather than on the learning generated through offshoring. While previous research suggests the existence of specialized management capabilities for offshoring, it lacks a comprehensive understanding of what offshoring management capability comprises and, most importantly, of the process through which it is developed. In Table 1, we present an overview of research suggesting the importance of studying offshoring management capability.

Previous research provides a foundation on which to develop a capability perspective of offshoring as several studies explicitly suggest the importance of considering offshoring capabilities. In a theoretical study, Levy (2005, p. 686) stresses why a capability perspective should be adopted by arguing that offshoring is "related to the development of firm-level organizational and managerial capabilities to coordinate geographically dispersed networks of tasks and productive activities." In another theoretical study, Doh (2005, p. 699) similarly notes that "offshoring potentially constitutes a firm-level capability". In addition, Bhalla et al. (2008) suggest that the costs associated with developing an offshoring capability may explain their inconclusive findings regarding the link between offshoring and firm performance.

A few studies also suggest specific factors that might constitute elements of offshoring management capability. These studies aim primarily to understand offshoring performance by identifying various performance drivers. Most notably, previous research argues that coordination capabilities are important for creating value through offshoring, because geographically dispersed knowledge needs to be transferred and integrated (Mukherjee et al. 2013). Similarly, Whitaker et al. (2010) proxy coordination capabilities using IT coordination applications (e.g., enterprise resource planning or customer-relationship management software) and find that firms using such applications are more likely to offshore. In addition to coordination, other factors can improve offshoring performance. For instance, Ramasubbu et al. 


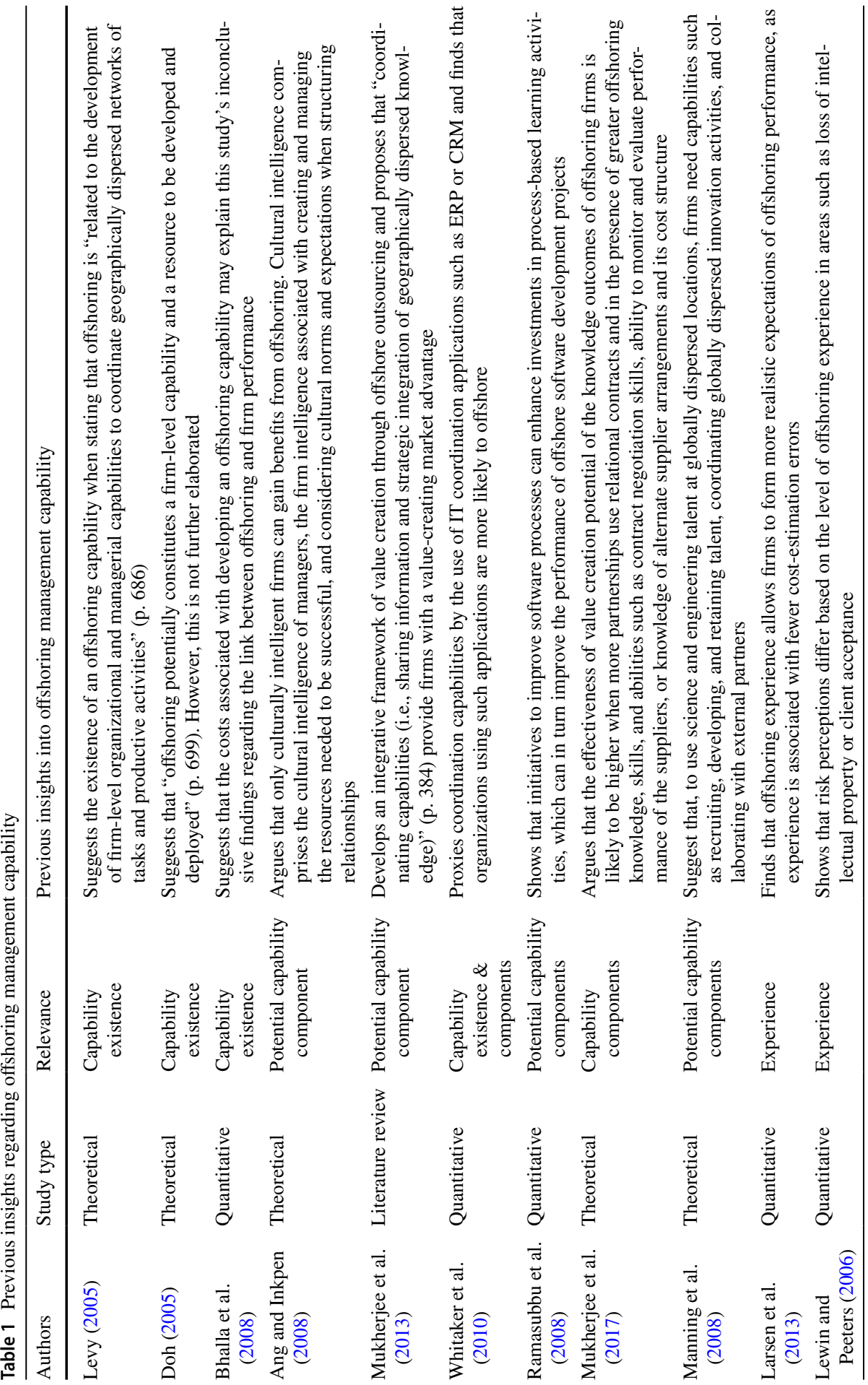




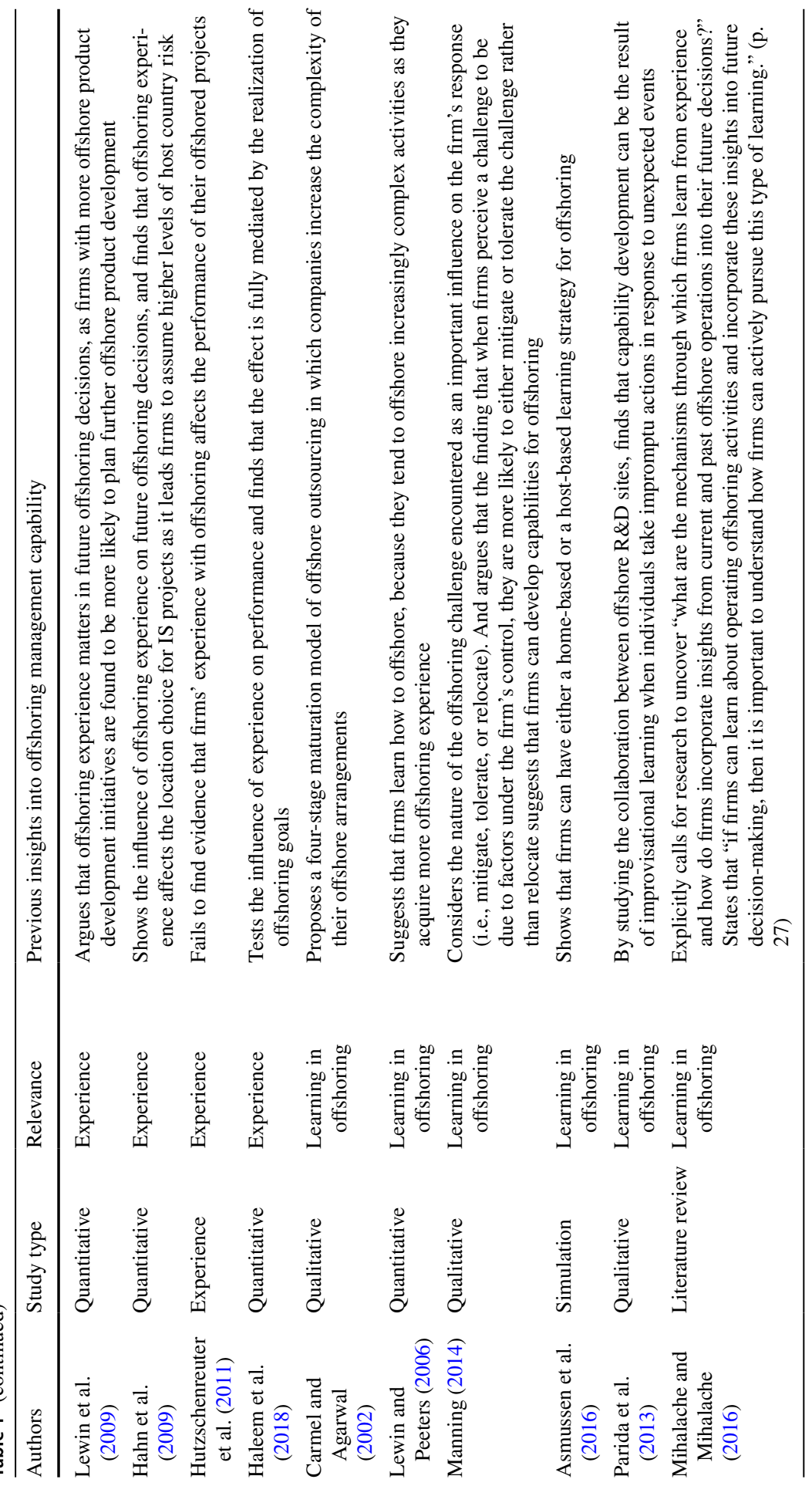


(2008) find that there is a positive association between the amount of effort spent on process improvement and the performance (i.e., productivity and quality) of offshore software development projects and that investment in learning activities mediates that relationship. Manning et al. (2008) suggest that, to use science and engineering talent at globally dispersed locations, firms need capabilities such as recruiting, developing, and retaining talent, coordinating globally dispersed innovation activities, and collaborating with external partners. In a theoretical study, Mukherjee et al. (2017) argue that an offshoring firm can exploit its knowledge more effectively for value creation when its partnerships with its offshore partners are more collaborative and use relational contracts. They argue that this will also be the case when the firm has more offshoring knowledge and skills, such as contract negotiation skills, the ability to monitor and evaluate the performance of suppliers, or knowledge of alternative supplier arrangements and its cost structure.

Another building block is provided by several quantitative studies that find that offshoring experience affects future offshoring decision-making. For instance, Larsen et al. (2013) find that experience is associated with better costs estimates due to better understanding of offshoring complexity. Experience is also important as it can alter firms' perception of risk; Lewin and Peeters (2006) find that firms with more offshoring experience perceive there to be lower levels of risk in terms of loss of intellectual property or whether clients will accept a particular service being provided by an offshore party. Similarly, Lewin et al. (2009) find that firms that already offshore product development activities are more likely to offshore additional product development than those that do not yet have any such activities abroad and Hahn et al. (2009) find that firms with more offshoring experience are more likely to place projects in locations with a higher host-country risk. Interestingly, the empirical findings on how experience affects offshoring performance is mixed, with some finding there to be a positive relationship between the two (Haleem et al. 2018), while others find no such relationship (Hutzschenreuter et al. 2011). These contradictory results suggest that it is still not clear how experience can be transformed into specialized capabilities for managing offshoring.

Another group of studies suggests that organizations can learn how to offshore. One notable finding is that, over time, organizations increase the level of sophistication of the activities they offshore and their perception of offshoring also starts to shift; they no longer see it as being simply a potential cost-saving measure but as playing a more significant strategic role (Carmel and Agarwal 2002; Lewin and Peeters 2006). Manning (2014) studies how the nature of the offshoring challenge affects the organizational response (i.e., mitigate, tolerate, or relocate). He argues that his finding that when firms perceive a challenge to stem from factors under their own control they are more likely to either tolerate or mitigate it, rather than to relocate operations, suggests that organizations can develop capabilities to manage offshoring operations. While these studies suggest that learning does take place in offshoring, they do not explicitly investigate the learning process. The few studies that do directly consider this, do so by considering different types of learning. One of these studies is a simulation study that argues that firms can have either a home-based or a host-based learning strategy for offshoring (Asmussen et al. 2016). Another notable study in this regard is Parida et al.'s (2013), which finds that 
capability development in offshoring can be the result of improvisational learning when individuals take impromptu action in response to unexpected events. Therefore, although we already know that learning can take place in offshoring, we lack a clear understanding of the process through which firms develop capabilities for offshoring.

What this literature review shows is that offshoring management capability has not been rigorously conceptualized thus far, since in previous studies it has mostly been considered as one of the implications of the research, rather than as the actual object of study. Although several important building blocks are already in place for a capability perspective of offshoring, there has been no dedicated and systematic effort to understand offshoring management capability. When suggesting potential elements of offshoring capability, studies to date tended to focus on individual offshoring initiatives rather than considering the entire portfolio of offshoring activities. That is, these previous studies typically focus on individual factors that might be related to the performance of a particular offshoring project; in order to develop a robust understanding of offshoring management capability, however, the level of analysis needs to move from the offshoring project to the firm level, where learning takes place. Furthermore, as previous research tends to be either theoretical or to focus on a single potential element of capability, more empirical exploration is required to identify precisely what constitutes offshoring management capability.

In addition, an important take-away of this literature review is that while we know that experience influences offshoring decisions, there are mixed findings regarding whether organizations can transform their experience into better offshoring performance, and it is also unclear what that learning process might be. In their systematic review of the offshoring literature, Mihalache and Mihalache (2016, p. 1129) explicitly call for future research to uncover how organizations "incorporate insights from current and past offshore operations into their future decisions?" Therefore, the goal of this study is to explore, by building theory based on evidence from the Dutch IT industry, what an offshoring management capability comprises and how organizations can develop it.

\section{Research Methodology}

As we aim to uncover the components of offshoring management capability and the way in which organizations develop it, we conduct an explorative study using multiple cases. This analytical method allows us to study our chosen phenomenon in practice (Van de Ven 2007), to observe how a contemporary set of events over which we have little or no control evolves across different organizations (Yin 1984), and to mobilize multiple, non-idiosyncratic observations of complex processes (Eisenhardt and Graebner 2007). Previous authors consider a case study approach as being suitable for stimulating new theoretical ideas (Edmondson and McManus 2007; Eisenhardt 1989). This is appropriate for our study, as we seek to uncover what comprises offshoring management capability and how firms develop it. The use of multiple cases increase the study's external validity as it improves the robustness of the findings (Eisenhardt and Graebner 2007). 


\subsection{Study Setting and Case Descriptions}

We used a theoretical sampling method (Eisenhardt 1989; McCutcheon and Meredith 1993), selecting organizations that we expected to be involved in offshoring. For this, we chose to focus on the IT service industry. This industry is an appropriate setting for this research because previous studies indicate it to be an early adopter of offshoring and because offshoring is used extensively (Olsson et al. 2008; Carmel and Agarwal 2002), as organizations attempt to improve their performance (Feeny and Willcocks 1998). In addition, IT organizations develop competencies in offshore locations for advanced services (Manning 2013), and therefore offshore more knowledge intensive processes, which require more coordination between onshore and offshore operations. By focusing on a single industry, we avoid the risk that sources of extraneous variation might conflate our findings (Eisenhardt and Graebner 2007).

In order to identify suitable cases to include in our study, we started with a search on Orbis-a database listing all organizations registered with the Dutch Chamber of Commerce-and obtained a list of active companies registered in the "Computer programming, consultancy and related activities" sector in the Netherlands. We then invited organizations by telephone to take part in an interview and fill in an on-line questionnaire. Because we wanted to learn about developing offshoring capabilities, we were interested in organizations for whom offshoring is a central part of their business model. IT service providers-organizations that provide IT services for other organizations-tend to offshore extensively to gain competitive advantage and thus are more likely to develop offshoring capabilities than organizations that only offshore their IT department. In other words, IT service providers are more likely to become experts in offshoring. Because we are interested in how organizations learn to offshore, we considered only organizations that have become highly successful at offshoring. We checked this using a questionnaire before arranging the interviews.

In all, we analyzed five cases because we considered that the research had reached a saturation point and new concepts were no longer emerging. This number of cases falls within the range of four to ten cases recognized in previous studies as being typical for case study research (Eisenhardt 1989). All the cases selected fulfill our criterion of having achieved a high level of expertise in managing offshoring. One of them rated its satisfaction with offshoring at five on a seven-point scale (i.e., slightly above expectation), whilst the other four all gave a rating of six (i.e., considerably above expectations). These ratings, together with qualitative statements made in the interviews, indicate that the companies included in this study are highly successful at offshoring. Below, we provide a short description of these five organizations and a summary in Table 2 . In order to obtain high quality data, we promised our respondents confidentiality and, consequently, we use pseudonyms to refer to the five cases and job titles rather than individual names.

\subsubsection{Alpha}

Alpha is the Dutch subsidiary of a large international IT services provider. In 2004, Alpha started offshoring to India, where it has around 400 employees. The offshore operations are fully owned subsidiaries of Alpha. The main driver of offshoring is 


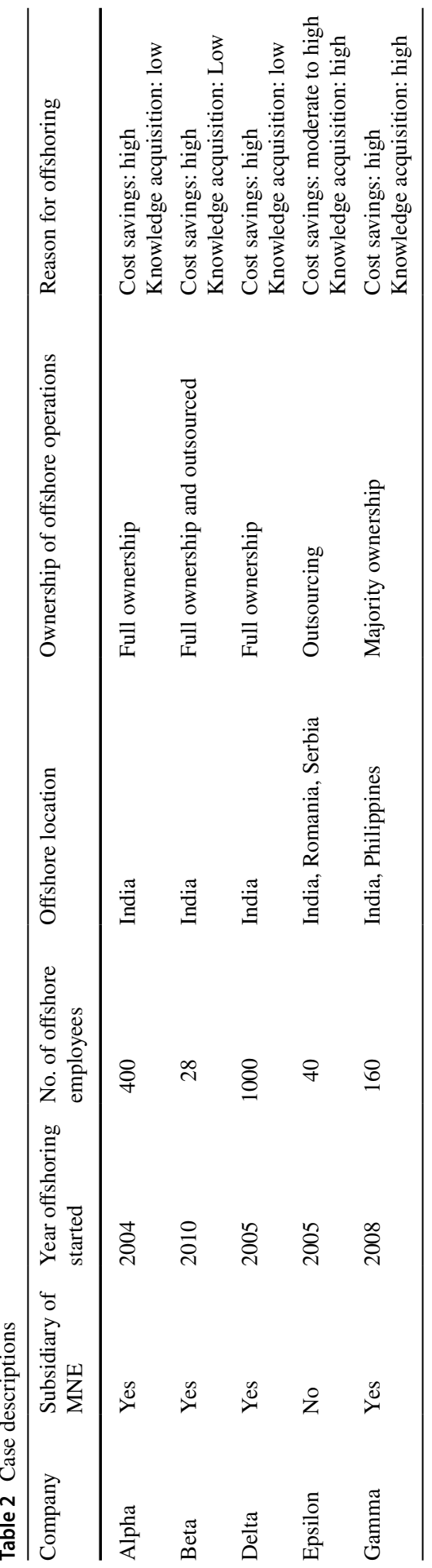


reduced costs when developing IT solutions for clients. In order to reduce costs, a large proportion of Alpha's activity takes place offshore; as much as $60 \%$ of its knowledge-intensive activities and $80 \%$ of its labor activities are in offshore centers.

\subsubsection{Beta}

Beta is the Dutch subsidiary of a large international provider of technology solutions. It started offshoring in 2010. It uses both foreign subsidiaries (captive offshoring) and external providers (offshore outsourcing). Only about 20\% of Beta's activities are performed offshore, and it currently has about 30 offshore employees. Beta offshores to India, and the main reason for the decision to offshore is costreduction. While this company initially had some problems with offshoring, it has invested time into building relationships and is now satisfied with the performance of its offshoring activities.

\subsubsection{Delta}

Delta, the Dutch subsidiary of an international provider of business applications, has significant offshore operations, with around 1000 employees. Delta's captive offshoring operations are located in India. It started offshoring in 2002 as a way of reducing its costs. Delta carries out about $40 \%$ of its knowledge intensive processes and $70 \%$ of its labor-intensive processes abroad. Although it is now satisfied with the performance of its offshoring operations, Delta has had to overcome considerable challenges due to the cultural distance between its home employees and their offshore counterparts. It overcame these challenges primarily by relocating key offshore employees to the Netherlands to act as a bridge between the home and the offshore operations, and by trying to incorporate aspects of the foreign culture into its domestic work practices and vice versa.

\subsubsection{Epsilon}

Epsilon is a Dutch IT solutions provider. It engages primarily in offshore outsourcing. While it started by outsourcing to India, it is increasingly moving to Eastern European countries such as Romania and Serbia because of the lower cultural distance. Epsilon offshores to reduce costs, but also to acquire knowledge. It started offshoring in 2005, and declares itself to be very satisfied with the quality of its offshore providers and the cost-reductions achieved, but acknowledges that it would like to improve further the delivery speed of its offshore operations.

\subsubsection{Gamma}

Gamma is the Dutch subsidiary of a multi-national IT solutions provider. It started offshoring in 2008, using the parent company's offshore centers in India and the Philippines. It currently has about 160 employees in offshore locations. Gamma tends to offshore processes that are labor-intensive and, usually repetitive, while performing most knowledge-intensive tasks domestically. It uses offshoring to reduce 
costs, but also because it provides them access to knowledge from the offshore services it shares with its mother company.

\subsection{Data Collection and Analysis Method}

We collected data using multiple methods, including conducting interviews, collecting questionnaires, and accessing publicly available data. We started the data collection process by administering a questionnaire to gather basic information on organizations' offshoring activities (e.g., satisfaction with offshoring, number of employees offshore, type of activities offshored, level of sophistication, location, and governance mode) and general information about the organization (e.g., size, age, and ownership). The questionnaire served a dual purpose. First, as mentioned in the preceding section, it helped us pre-screen organizations for inclusion in the study by giving us a quantitative indication of their offshoring performance. We used this basic data to rank the organizations in terms of how much we considered they could help us build a theory about the development of offshoring management capability. Second, we used the basic information about the firms and their offshoring activities to prepare for the interviews by tailoring our questions to get the most out of our interview time. Our informants for the questionnaires and interviews held positions such as manager of global sourcing, senior consultant, solutions architect, or senior delivery manager.

Second, we conducted semi-structured interviews with personnel responsible for offshoring activities at our case companies. We interviewed two high-level respondents in each company. We chose to use semi-structured interviews because the research question was exploratory, and we wanted to be able to probe more deeply into relevant issues that came up during the interview. This also meant that we improved the semi-structured interview protocol over time as we discovered more about the research question (Glaser and Strauss 1967). We developed initial questions from the literature, focusing on three main areas: general information on the organizations and its offshoring activities, offshoring performance, and offshoring challenges and their solutions. The interviews were conducted in person in the respondents' native language (Dutch) to ensure smooth communication and avoid misunderstanding of academic terms. The interviews lasted on average for $60 \mathrm{~min}$ and were recorded. Bilingual researchers then translated the write-ups into English. We complemented the information from the questionnaire and interviews with information from company records and publicly available data about the case firms.

We analyzed data to develop our grounded theory model by following Gioia et al.'s (2013) systematic methodology for analyzing qualitative data. We first opencoded the interviews to obtain first order categories in the data. Then, we moved from open to axial coding to consolidate first-order constructs and raise their level of abstraction into second order themes. We then analyzed these second order themes to suggest concepts (third order aggregate dimensions) that might explain the phenomenon we are studying. We coded the interviews using the qualitative coding software NVivo. In order to ensure reliability, another researcher also coded the 
interviews and disagreements were resolved through discussion. Figure 1 shows our data structure.

\section{Findings}

A key finding from our cases is that the offshoring management capability is multidimensional, comprising coordination competency, relationship development, relationship design, and organizational identification development. In addition, we uncover the process through which organizations can develop an offshoring management capability. This requires organizations to implement a learning loop consisting of offshoring growth mentality and mechanisms for adaptive monitoring of offshoring performance, offshoring reflexivity, and storage and dissemination of offshoring best-practice. Below, we discuss in detail each element of the offshoring management capability and the learning loop that organizations employ to improve their offshoring management capability. Figure 2 depicts our inductively derived model.

\subsection{Offshoring Management Capability: Coordination Competency}

Essentially, all the cases revealed the importance of developing an ability to coordinate operations that are geographically dispersed. Srikanth and Puranam (2011) consider coordination in offshoring software services to be so important that they conceptualize the organization as a coordination system. However, coordination in offshoring is difficult due to geographical distance that increases transaction costs (Handley and Benton 2013). Coordination is further hampered by cultural differences, which are associated with different predispositions for tacit and explicit knowledge (Lehrer and Asakawa 2003), status differences between countries (Levina and Vaast 2008), and differences in values (Pascual-Ezama et al. 2015). Interestingly, our case companies were able to deal with these difficulties of coordinating offshore operations by employing a variety of practices.

When discussing how to overcome the hurdle of coordinating dispersed operations, respondents stressed the importance of communication routines. They described that their organizations had implemented routines regarding the mode, frequency, and regularity of communication. In order to bridge geographical and cultural gaps, many companies implemented policies that focused on increasing the richness of communication modes. For instance, a senior manager at Alpha reported that: "We strive for a zero-email policy, we prefer to use the telephone and chat. An email is very formal, and we don't want that because it is timeconsuming. We are colleagues and we need to be able to approach each other as such." A manager at Beta voiced similar thoughts:"... sometimes you just have to pick up the phone instead of sending an email twice." In particular, using greater media richness can improve coordination in virtual organizations because it increases information-processing capacity (Daft and Lengel 1986; Jensen et al. 2009). In other words, firms can implement policies that guide employees towards 


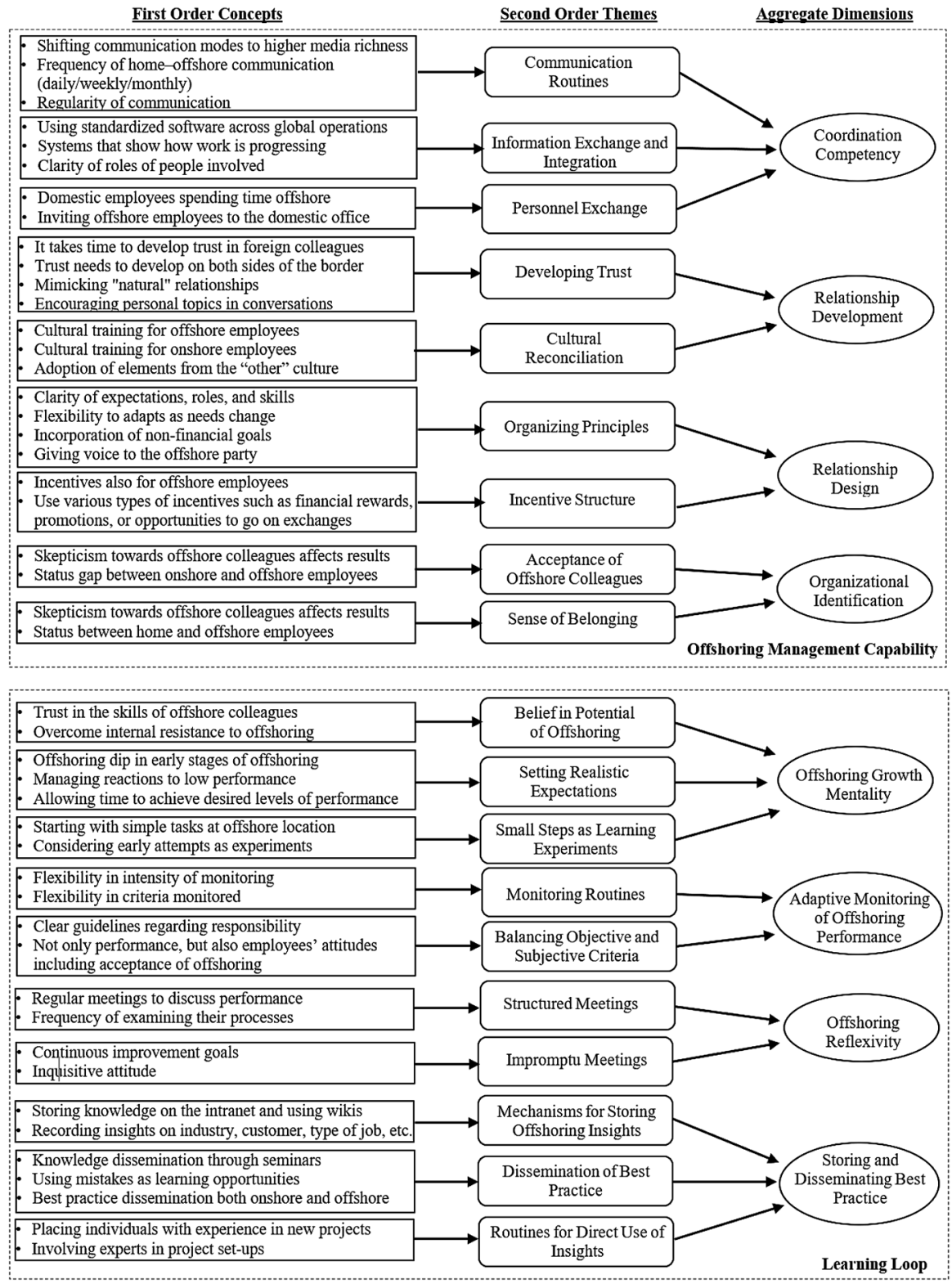

Fig. 1 Data structure

using methods of communication that try to emulate those employed when working with colleagues in the same building.

In addition, the companies in our sample established policies regarding the frequency and regularity of communications with offshore operations. Establishing regular and more frequent communication helped the organizations we analyzed 


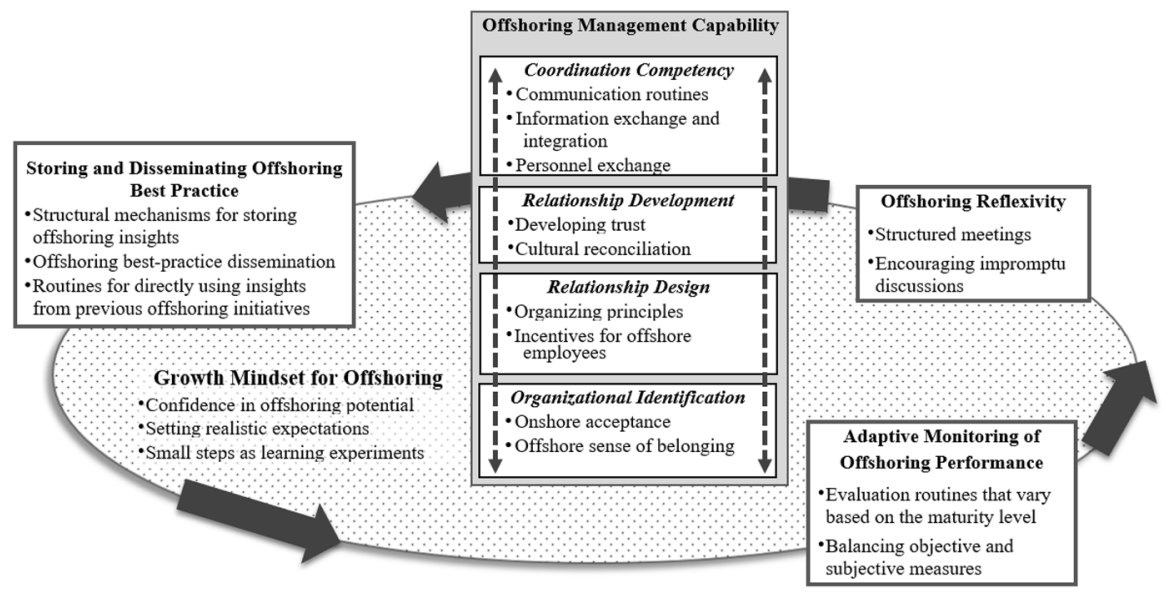

Fig. 2 Offshoring management capability and its development

reduce misunderstandings associated with differences in inter-cultural communication. For instance, at Beta, meetings were not only frequent, but were also held at regular times:

"Every day at 11:30, I call the manager in India and we discuss daily events, from their side and our side. This gives a good overview of what is going on. In the beginning, we only had a call every Friday but this was not enough. Calling every day is essential because it enables you to switch quickly between issues. In addition, every Friday at 09:00 in the morning, we have a team meeting, where everybody can say what they want to say. This works very well."

Similarly, a manager from Gamma also described the communication practices that helped the firm improve coordination with offshore operations: "I communicate sometimes daily with the offshore team and I am never really disappointed. They always respond within a day... Frequent communication is essential." Thus, in order to develop coordination competencies, firms can implement communication procedures that encourage employees to use rich communication media and to communicate frequently and regularly. One respondent summarized the above points about the importance of communication for coordination very nicely when stating Epsilon's philosophy on communication: "The richer and more frequent communication is, the easier it is [to coordinate offshore activities]."

In addition to communication routines, our case evidence suggests that ensuring information exchange and integration between offshore and onshore operations is a key element of successful coordination. Most of our case companies were able to ensure knowledge exchange by establishing a technological infrastructure to connect onshore and offshore operations. By using IT systems that integrate information from different geographical sites and make it possible to track the progress of work at different locations, a firm can help its employees to coordinate work despite 
the geographical distance. Geographically distant colleagues can access information regarding the progress of work at different locations, and then plan their tasks accordingly. For instance, a manager described Delta's technological infrastructure, which allows staff to exchange knowledge between geographically distant sites:

"When an issue arises, a warning light flashes. Someone will log in and see if they can resolve the issue... Also a notification of the fact that an issue was reported is recorded. The notification is recorded because it could happen again when somebody else is on duty. They should be able to access the solution. This all happens in the same system. It is more or less one big knowledge base. This system is also used to make reports. At the end of the month, the service manager can use this system to create graphs and analyses. He will add some comments and put it all in a document."

In relation to the above point, Alpha's practice of standardizing information exchange systems across global operations appears to be crucial for coordination: "...we have the same document management system all over the world. English is our formal language. Everyone is on the same network and we have a chat system." Describing their efforts to increase coordination, a manager at Alpha said that his organization enabled knowledge exchange through the technological infrastructure by establishing clear global roles: "all the formal aspects of communication, process descriptions and responsible persons, are all stored. These process descriptions are vital to make it clear who has the lead in certain projects. All the roles are the same globally."

A third way of ensuring coordination is to set-up personnel exchanges between offshore and onshore operations. Personnel exchange improved coordination in several of our cases, as it developed connections between individuals, helping them to synchronize work, and taught them about the roles and responsibilities of geographically distant colleagues. A Solution Manager from Alpha stated: "We have an Indian colleague working here in the Netherlands fulltime, to make communication and cooperation easier. He knows who we can approach in India when we have certain issues." Beta employed a similar practice:

"We also transferred one member of the Indian team to the Netherlands in November, and he is working in the Netherlands with the Dutch team. I also guide him; he sees our culture, he sees how we work, and when he goes back to India... he will be the lead contact there. Then he will be our source of knowledge."

To summarize, our interview findings indicate that in order to develop coordination competency, firms need to establish communication routines, implement information exchange and integration platforms, and set up personnel exchanges.

\subsection{Offshoring Management Capability: Relationship Development}

Our data shows the importance of building strong relationships and indicates that offshoring firms need to invest in relationship development. As a manager at Epsilon 
reported: "A very important aspect is that you can only work well with each other when you have a solid relationship... If the relationship is not harmonious, the cooperation cannot be efficient...So, we work hard on building the relationship."

A key element of relationship development is developing trust, which is a lengthy process. This is because, as one Gamma manager identified, developing trust requires "working with each other, listening, communicating, and making arrangements for certain projects". Trust also needs to be bi-directional: onshore employees need to overcome their reluctance to send jobs abroad and believe in the skills of offshore partners, while offshore employees need to be committed to the relationship and put effort into providing quality work. Trust in the other party is important, as it is associated with knowledge transfer (Westner and Strahringer 2010) and lower project costs (Rai et al. 2009). While trust is important, developing it in offshoring relationships is a challenge, due to the geographic and cultural distance between the parties. Our case evidence strongly indicates that to develop trust it helps to mimic 'natural' relationship development. This means arranging face-to-face meetings and communicating not only on a business level, but also on a personal one. Several respondents emphasized that their organizations developed trust by using this approach:

"In virtual communication you miss verbal communication. We try to see each other quite regularly, especially when it is a long relationship. At the start of new projects, we invite three or four Indian project team members to the Netherlands; they stay for a while and then take the work back to India. They will tell their Indian colleagues how the project will be managed." (Beta manager)

"[Offshore employees] look at us as if we are guys in a far-off country. In that case, what often works is having a representative of an offshore team here in the Netherlands some time. Then it not just "those guys over there," you establish face-to-face contact. Face-to-face contact initially helps build up trust. In my experience, that helps a lot." (Alpha manager)

In addition, our respondents found that their organizations developed trust more easily when conversations went beyond business and into personal issues. For instance, a manager from Beta states:

“...it is important to talk not only about work but also about private life. I also notice that when you do this they trust you very quickly. I think this a culture thing...in India when you treat people with respect and show your interest in them, then they will return this, and this creates trust."

In addition, our case evidence indicates that cultural reconciliation is particularly important in developing a strong relationship with offshoring partners. Cultural differences hamper cooperation because they are associated with differences in expected behavior and communication styles (Beugre and Acar 2008). Building on this insight, Clampit et al. (2015) argue that the degree of cultural complementarity between onshore and offshore employees is a key driver of satisfaction with the offshoring relationship. Our findings advance these studies by indicating that organizations can actively manage cultural differences in offshoring and revealing several ways in which they can do so. 
An important insight from our data is that developing an understanding of each other's culture is particularly important for developing a working culture. First, to increase awareness of cultural differences and develop the tools to cope with these differences, several case companies arranged for employees who dealt with offshoring to attend cultural training courses. For instance, a manager at Epsilon said of his company's investment in cultural training: "What helps a lot is ordinary, simple cultural training. Dutch people who deal with offshore projects give [offshore colleagues] a course on cultural difference (business and national) in order to bridge the fundamental differences between countries." A consequence of cultural training is that it can make people more flexible in dealing with other cultures. This is manifested by incorporating some elements of the foreign culture into domestic work practices; that is, adjusting to the foreign culture to some extent in order to help build a strong relationship. At Beta, for example, working practices were altered in order to allow a degree of adaptation to the offshore culture: "But I think that I managed to include some of their culture in our working habits... a lot of holidays, longer breaks and so on."

Cultural training both onshore and offshore also has benefits as it provides offshore employees with a better understanding of the culture of the organization's home country, leading to a smoother relationship. For this, our case companies invite offshore workers to spend time in the home office. A manager from Delta reported that:

"What we do to get them a little bit used to the western culture is to invite two employees from India to spend six weeks here in the Netherlands... They work with the Dutch team - this creates a lot of contact. Their boss also visited us for two weeks to ensure that on a tactical level we made good arrangements... There are however some employees, especially some who have already worked for us in India for a long time, who are already more direct. They have learned how to be direct and they have adapted to our western culture."

These practices suggest that culture can be managed and that both onshore and offshore employees can learn what to expect and how to adjust their behavior. The result is "cultural reconciliation" as employees from different parts of the world adapt their behavior a little in order to improve the working relationship.

\subsection{Offshoring Management Capability: Relationship Design}

A third dimension of offshoring management capability is the ability to design the offshore relationship by choosing appropriate organizing principles and incentive structures. Due to geographical and, sometimes, organizational boundaries, the offshore and domestic employees might perceive themselves to have different interests. Consequently, relationship design aims to align the interests of the offshoring organization and its offshore affiliates. 
A key element of relationship design, particularly for offshore outsourcing, is choosing appropriate organizing principles. Existing research largely focuses on understanding the choice between fixed-price and time-and-materials contracts and shows that the contract type depends on vendor and client preferences (Gopal and Sivaramakrishnan 2008) as well as project characteristics (Gopal et al. 2003). Our fieldwork shows that organizations that have offshoring capabilities go beyond contract choice to think in terms of the organizing principles involved in designing the relationship. In the organizations we studied, these principles were clarity, flexibility to cope with changing needs, incorporation of non-financial goals, and co-development with the offshore party. For instance, an Alpha manager described his company's approach to relationship design as follows:

"It is often necessary to ask the right questions. You have to put your expectations up front, before you start. Often, people avoid this. You have to remember you are working with people from different cultures, you have to be very specific and make sure that everybody understands everything the same way. Often, misunderstanding is just a matter of miscommunication. So you have to be very explicit...it is useful to put everything down in black and white; what you can do and what you cannot do with regard to deadlines."

However, as many projects are fluid and specifications can change, our respondents indicated that they tried to design contracts with a degree of flexibility to accommodate changing needs. A Delta manager said: "When you sign a contract, you agree on what you will do and how you will achieve certain things, but things always change as you go on. When you say you need a solution to make something work, then the employees in India are perfectly capable of coming up with a solution. It is more a matter of how you ask your question."

Part of this flexibility comes from including non-financial goals such as client satisfaction in the contract, as an Epsilon manager described:

"The contract states that you have to help me satisfy the customer and not build a certain thing. For me it is important that we measure client satisfaction rather than how fast someone answers a client's question. When I tell suppliers that I will judge them based on growth, they will try their utmost to achieve this growth. This means that they have to be proactive. On the other hand, when I only specify [in the contract] the things they have to do in complaints situations, they will only stick to the things I have asked them to do. Of course, we do specify some things that have to happen, but this is not the main goal."

An additional tactic that can enhance the relationship design is to involve the offshore party in setting out what is expected and how they will deliver it: that is, giving the offshore party a voice in the process rather than imposing a set of requirements. A Beta manager outlined his organization's approach:

"We build a "living" document for us and for our offshore team. We record and store all agreements we make together in this document...At the start of our project we meet with the full project team. After the meeting, I send them 
this living document. If they want to make adjustments, they are free to do so. I think that this is a strong point because it gives them the feeling that they don't have to do something, but that they also have a say in the matter. This gives them the chance to make the project to some degree their own. This leads to a very relaxed atmosphere... I think it is important that both teams have their noses in the same direction rather than just following my nose."

The case companies show that the organizing principles need to be complemented with an incentive structure. A key insight is that all those involved in the project, including offshore employees, need to be incentivized, whether they are inhouse or outsourced. Our respondents mention the importance of rewarding the performance of offshore employees. In the words of an Epsilon manager: "If you are successful together, give everyone the credit they deserve for the achievement...So if we do it right, or do better than agreed in a contract, make certain that the subcontractor shares in the bonus...So you have maximum interest."

Another type of incentive involves supporting the professional growth of offshore employees. Several of our respondents acknowledged the benefits of offshore employees spending time abroad. Working at the domestic organization for a time is valuable for offshore employees, as it improves their status and professionalization. As such, bringing personnel from the offshore location to spend time in the homecountry organization can be a reward for high performance, as well as bringing benefits in terms of collaboration and cultural understanding, as discussed previously.

\subsection{Offshoring Management Capability: Organizational Identification}

The fourth element of offshoring management capability is the ability to make both onshore and offshore employees identify with the global organization. Organizational identification is "the perception of oneness with or belongingness to an organization, where the individual defines him or herself in terms of the organization(s) in which he or she is a member" (Mael and Ashforth 1992, p. 103). Identification with the global organization has many benefits; for example, it can strengthen employees' commitment to the organization, help them feel more positive towards others within the organization, and improve cooperation (Ashforth and Mael 1989). Conversely, perceiving particular employees as outgroup members can damage cooperation. As offshore and onshore employees are located across geographical and, sometimes, organizational boundaries, they often perceive each other as out-group members. An Alpha manager explicitly acknowledged the problems created by out-group perceptions: "Some colleagues are skeptical of or look down on our Indian colleagues. This type of underestimation is devastating for cooperation."

Our interviews indicate that to develop organizational identification that crosses geographical and, in the case of offshore outsourcing, even organizational boundaries, organizations need to work on strengthening organizational identification among both onshore and offshore employees. First, organizational identification requires domestic employees to accept their offshore colleagues as part of the team and not as second-class organizational citizens. Developing such perceptions takes 
time, as evidenced in several of our cases. Alpha, for instance, undertook such a transformation process:

"When we just started offshore outsourcing, we were in a demand-supply model. That is how we started. Now, we have grown and developed to such an extent that we see our partners in India etc. as equal and as colleagues. They have also developed themselves and are more confident... In the beginning we acted as a client and the contract described the workload we would transfer to the offshore country. This was very obscure for our Indian colleagues. They just waited until we had a task for them. Slowly this model changed to a global way of working. Now we are just all colleagues. It doesn't matter whether somebody from the Netherlands programs some code or whether it happens in India."

Second, organizations need to work on creating a sense of belonging in offshore employees; that is, offshore employees need to feel a sense of identification with the larger organization. To this end, our case companies employ several strategies to make offshore employees feel included. A common practice is that of inviting offshore workers to spend time with domestic employees in the Netherlands as this makes them feel appreciated and connected to the organization. An addition practice for increasing organizational identification in offshore employees is providing knowledge about the organization. An Epsilon manager described how he tries to develop a sense of belonging in offshore employees:

"When I visit Eastern Europe, I always tell them about Epsilon's vision and I always treat them as Epsilon employees even though they live in Eastern Europe and not in the Netherlands. You have to treat the partners as equals and stick to that mindset; this will help you progress and learn to strive for the same goals."

Another interesting tactic used by our case organizations to create a sense of belonging in offshore employees is to celebrate success together. A Beta manager said:

"We celebrate successes with the offshore team and ask for a budget for this. What I do now is I hold some of the budget back to do fun stuff with them. The result is that, when they know that they will be working with me, they are a lot more open and they go the extra mile because they know they are working with me. They like working with me and they know that they will maybe get something extra out of the budget. These are all small things but they really appreciate that."

\subsection{Developing the Offshoring Management Capability: The Learning Loop}

An important finding from our cases is that organizations can actively develop their offshoring management capability. For instance, Gamma staff mentioned they had learned a lot from previous offshoring projects, and they routinely drew on these insights in order to set up new offshoring initiatives differently: 
"On every level, there are signs that we can improve. This is recorded and communicated. We explore how we can improve structurally and use the knowledge of eighteen months of offshoring experience. We have learned especially about setting up activities before we start. We do things differently now when starting new activities."

We find that organizations can actively develop an offshoring management capability by establishing a learning loop that consists of an offshoring growth mentality, adaptive monitoring of offshoring performance, offshoring reflexivity, and offshoring knowledge storing and dissemination mechanisms.

For our case companies, the foundation for developing offshoring management capability was establishing an offshoring growth mentality. A key element to this is to create confidence in the potential of offshoring throughout the organizations and to overcome initial resistance. For instance, in several of our cases, it was important to convince domestic employees that offshore colleagues were sufficiently qualified for the work, particularly for providing the motivation to tackle early challenges. A second important aspect of an offshoring growth mentality is setting realistic expectations regarding the time it takes to start enjoying the benefits of offshoring. Several of our respondents talked about the importance of managing reactions to poor results in the early phases of offshoring as opponents of offshoring usually tried to use the 'offshoring dip' as a reason to halt offshoring. As one Delta manager emphasized, "we have to acknowledge that it will take us two to three years before the relationship starts to generate efficiency". A manager from Beta made a similar point:

"I see how other colleagues manage their outsourcing relationships. They have much too high expectations for too short a period. You cannot expect people in India to develop something in two weeks. They forget that [offshore employees] also need time to pick up new things. You have to give them some time."

A third element of a growth mentality is taking small steps and explicitly considering these as learning experiments. Using experimental learning (Levitt and March 1988), our case organizations started offshoring with a small number of simple tasks and, over time, increased the size and complexity of their offshoring projects. A Delta manager gave a good example of this small-steps approach:

"We initially started [offshoring] because of the good stories of [another company]. So we tested a couple of tiny pilot schemes in India, while keeping development in the Netherlands... But gradually we transferred more activities to India, like design and analysis, and we don't want to go back to the old situation."

While a growth mentality is important, it needs to be complemented by learning mechanisms. One important learning mechanism for developing an offshoring management capability is adaptive monitoring of offshoring performance. A Gamma manager stressed that flexibility is needed so that, if problems are identified, monitoring can then be made more stringent and more frequent. Similarly, as organizations expand the use of offshoring, the criteria monitored need to be adjusted to include more complex and advanced criteria to match changing 
offshoring goals. In addition, to help with monitoring, a Gamma manager said that clear guidelines are needed regarding who is responsible for what with regard to the offshoring initiatives. Furthermore, several case organizations showed that monitoring is required not only on objective measures of offshoring performance, but also on subjective ones such as employees' attitudes to offshoring. As a manager from Alpha reported: "after two years of following this strategy, some resistance to offshoring might have been reduced or even disappeared". Monitoring subjective criteria is important for learning, as the mindset of employees affects their willingness to develop and, consequently, influences the organization's ability to offshore more complex tasks.

Another learning mechanism that is crucial in the development of an offshoring management capability is offshoring reflexivity. Reflexivity refers to the extent to which firms reflect on and adapt their objectives and processes (Tjosvold et al. 2004). That is, reflexivity goes beyond monitoring of performance to question the underlying causes of the outcomes. For a firm to develop an offshoring management capability, the reflexivity is paramount as it serves as the basis for developing insights and identifying best practice. Data indicates the benefits of having both structured processes for reflexivity such as monthly meetings and impromptu reflexivity sessions. Gamma, for instance, organizes monthly meetings to discuss offshoring performance and identify performance drivers. Similarly, an Epsilon manager described his company's practices by stating that "we periodically evaluate everything we do... in order to determine the lessons learned and to improve". Regarding impromptu reflexivity sessions, this manager added that, in addition to structured meetings, they also reflect on process issues as these arise.

The next step in developing an offshoring management capability is storing and disseminating offshoring best practice. As an Epsilon manager pointed out, insights and offshoring best practice are recorded on intranets and wikis, allowing organizational members to access this information easily. Epsilon also disseminates offshoring best practice through seminars at which lessons from previous offshoring initiatives are discussed in order to prevent the same problems re-occurring:

"We try to encourage learning from each other's mistakes. We have knowledge sessions at which we discuss a few spectacular failures. The goal of these sessions is not to burn [punish] the people who were responsible for the failures; the goal is to share the experience."

Importantly, dissemination of offshoring best-practice needs to go beyond the home-country setting and reach offshore colleagues as well to ensure these insights are used by all the relevant parties. As one of the managers emphasized:

"We started relatively early with offshoring and we learned from the mistakes we made. One of the things that has changed is that there is now an increased focus on the sharing of information with our Indian departments. By using the same systems and tools, we are able to ensure that there is an optimal flow of information." 
In addition, for learning, organizations need routines that allow them to make use of the insights they have acquired. Such routines can include using employees with specific knowledge of a particular country or offshore partner as project members or in the setting up of the new project.

\section{Discussion}

\subsection{Theoretical Implications}

This study contributes to offshoring research by developing a capability perspective of offshoring. Offshoring management capability refers to the ability of firms to setup and manage a portfolio of offshoring activities to achieve their strategic goals. A key contribution of this study is that we find that the offshoring management capability is multidimensional and uncover its elements. By doing so, the study advances previous research that suggests the existence of offshoring capabilities (Bhalla et al. 2008; Doh 2005; Levy 2005). Furthermore, the finding of the offshoring management capability's multidimensionality contrasts previous studies that suggested isolated factors that might be important for offshoring (e.g., Ang and Inkpen 2008; Manning et al. 2008; Mukherjee et al. 2013; Whitaker et al. 2010).

Our study adds to these important previous efforts by providing a more comprehensive understanding of offshoring management capability and its dimensions. Such a comprehensive approach is important because the underlying dimensions are interrelated; that is, an offshoring management capability is more than the sum of its parts, because its dimensions reinforce one another. For instance, because trust stimulates knowledge exchange (Westner and Strahringer 2010), relationship development can promote coordination competency. Also, relationship design can enhance the development of organizational identity as aligning incentives between home and offshore employees can contribute to the sense of belonging. Similarly, organizational identification can help relationship development as the sense of belonging can help make employees more receptive to cultural reconciliation. Furthermore, the four dimensions are interrelated because some of the mechanisms used to stimulate one dimension can also stimulate others. For instance, from the interviews it became clear that personnel exchange could increase not only coordination, but also relationship development and organizational identification. The comprehensive approach to offshoring management capability advanced in this study is therefore important because of its underlying dimensions' mutually reinforcing nature.

In addition, our study uncovers the mechanisms needed for the four dimensions of offshoring management capability. We add to previous insights that coordination capability is important for creating value through offshoring (Mukherjee et al. 2017; Whitaker et al. 2010), by uncovering that firms can stimulate coordination by establishing communication routines, mechanisms for information exchange and integration, and arranging personnel exchange. Also, we advance previous research proposing the importance of building relationships with offshoring affiliates for production transfer (e.g., Aaboen and Fredriksson 2016) by uncovering the mechanisms for relationship development-developing trust and cultural reconciliation. 
Furthermore, our study uncovers two novel elements that also form part of offshoring management capability: relationship design and organizational identity development. Our findings regarding relationship design highlight the importance of going beyond the focus on contract type found in previous research (Gopal and Koka 2010). An offshoring management capability requires two shifts in perception or focus: first, viewing offshoring not purely as a transaction but as a longer-term relationship, and second, focusing not on contract specificity but on the principles underlying the relationship. Lastly, our finding regarding the importance of organizational identity development underscores the importance of investing in a culture of 'togetherness'. Together, our findings show that offshoring management capability is more complex than previously conceptualized. The more comprehensive view of this capability provided by this study highlights the need for organizations to consider the various dimensions of the capability simultaneously.

The study also contributes to offshoring research by showing that organizations can develop an offshoring management capability and by revealing that they can do so by taking a structured approach to learning from experience. We find that, to support learning, organizations created a learning loop that is founded on an offshoring growth mentality. This can be achieved by inculcating a sense of confidence in the potential of offshoring, setting realistic expectations, and using small offshoring initiatives as learning experiments. The growth mentality supports the learning loop, other elements of which include adaptive monitoring of offshoring performance, reflexivity, and the storing and dissemination of offshoring best practice. Specifically, we found that monitoring and reflexivity provided firms with a systematic way of understanding and improving their offshoring management capability and that firms had put in place routines for store and using offshoring best practice.

The learning process for the offshoring management capability stimulates development in all its four dimensions. Since no differences were found in terms of how the various dimensions were developed, we conclude that the learning loop works by stimulating development of all four of them. This is in line with previous treatments of learning in offshoring as a general organizational-level process (e.g., Asmussen et al. 2016). A general organizational-level process is also in line with our finding that the dimensions of offshoring management capability are mutually-reinforcing. That is, developing one dimension has influence on the development of the other dimensions. Furthermore, our findings show that organizations need to be proactive and put in place structured learning mechanisms do develop offshoring management capability. While learning in offshoring can happen in an impromptu fashion (Parida et al. 2013), our findings suggest that this is not sufficient for the development of offshoring management capability, since learning is not a one-off event. As investments in structured processes can lead to learning (Ramasubbu et al. 2008), our study shows the importance of establishing a learning loop that enables continuous learning. Thus, our study suggests that developing an offshoring management capability is a deliberate activity that requires continuous managerial attention. This point is particularly pertinent as, oftentimes, offshoring involves interacting with parties outside firm's boundaries (Lahiri et al. 2012).

Overall, by explicitly uncovering the learning process through which firms develop offshoring management capability, our study answers Mihalache and Mihalache's (2016 p. 1129) call for this process to be better understood as made 
in their observation that "if firms can learn about operating offshoring activities and incorporate these insights into future decision-making, then it is important to understand how firms can actively pursue this type of learning". That is, the learning process we uncover advances previous research that argued that organizations learn how to offshore but that did not focus on the process through which such learning occurs (Carmel and Agarwal 2002; Lewin and Peeters 2006). While it has been acknowledged in previous studies that experience influences offshore decision-making (Gerbl et al. 2015), this study takes that idea forward by showing the process through which firms actually leverage that experience to develop an offshoring management capability.

\subsection{Practical Implications}

Our findings have several important practical implications for organizations engaging in offshoring. By uncovering the four dimensions of the offshoring management capability (i.e., coordination competency, relationship development, relationship design, and organizational identity development), we highlight the factors that allow organizations to be successful at offshoring. The finding that the offshoring management capability is multidimensional suggests that managers should adopt a holistic approach when considering what it takes to achieve the full potential of offshoring. That is, it is not enough for them to focus on a single factor such as coordination or contract design; they need to take multiple factors in consideration. Furthermore, our study shows how organizations can develop an offshoring management capability by implementing structured mechanisms for organizational learning. While many organizations stop offshoring when they encounter early setbacks, we find that when managers believe in the potential of offshoring and have realistic expectations (i.e., that it might take two to three years before they see positive outcomes) they can spark a learning process. To build their capability to offshore, organizations need not only to foster a growth mentality but also put in place specific mechanisms that enable them to learn from their experience. That is, they need mechanisms that take insights from the performance of individual offshoring projects and use them at the organizational level. Such mechanisms include adaptive monitoring and reflexivity. To identify best practice, it is important to know what aspects of performance to monitor performance and to setup routines for reflection, such as meetings at which managers examine the underlying causes of performance. In addition, organizations need to store offshoring best practice and disseminate it to relevant parties both onshore and offshore. Therefore, managerial intentionality is fundamental for the development of an offshoring management capability as it requires the deliberate implementation of structured processes to stimulate learning.

\subsection{Limitations and Future Research}

While this study makes several important contributions by developing a capability perspective of offshoring, it nevertheless has its limitations. There is thus scope for its insights to be built on in future research in a number of ways. Our study uncovers several dimensions of the offshoring management capability but does not explain 
their relative importance in different situations. That is, as organizations have limited resources in terms of finance and managerial attention, future research could try to identify which dimensions they should prioritize. As projects are associated with different types and levels of risk (e.g., Ellram et al. 2008; Liu et al. 2011), future research could consider the relative importance of the dimensions of offshoring management capability in different situations-for example, when pursuing different types of goals (e.g., cost reduction versus knowledge acquisition). The relative importance of dimensions could also be analyzed when offshoring to developed versus developing countries as differences in their development create differences in transaction costs (Martinez-Noya et al. 2012) and risks (Hahn et al. 2011). The offshoring motives and country characteristics are themselves related as countries' idiosyncratic competencies attract offshoring initiatives with particular goals (Bunyaratavej et al. 2008; Jensen and Pedersen 2011). Future research could address these limitations of our study through quantitative approaches.

Another limitation of our study is that it looked only at the Dutch IT industry; this could be addressed by expanding the focus to other industries. While we focused on a specific industry where offshoring management capabilities were most likely to be observed, future studies could build on our efforts to understand what offshoring management capability is and how firms develop it by testing our findings on a larger set of industries. An additional fruitful area for future research would be to attempt to understand which organizational and managerial factors enhance the development of offshoring capabilities. As previous research has shown that the characteristics of the senior management team affect the organization-level consequences of offshoring (Mihalache et al. 2012), future research could consider whether certain management team characteristics help firms to develop offshoring management capabilities.

\section{Conclusion}

Our study puts forward a capability perspective of offshoring by providing a comprehensive understanding of what an offshoring management capability is and uncovering the process through which organizations can develop it. A key implication of our study is that organizations need to be aware of the offshoring management capability's multidimensionality and that they need to implement a structured process for learning to develop it.

Open Access This article is distributed under the terms of the Creative Commons Attribution 4.0 International License (http://creativecommons.org/licenses/by/4.0/), which permits unrestricted use, distribution, and reproduction in any medium, provided you give appropriate credit to the original author(s) and the source, provide a link to the Creative Commons license, and indicate if changes were made.

\section{References}

Aaboen, L., \& Fredriksson, A. (2016). The relationship development aspect of production transfer. Journal of Purchasing and Supply Management, 22(1), 53-65. 
Amit, R., \& Schoemaker, P. J. H. (1993). Strategic assets and organizational rent. Strategic Management Journal, 14(1), 33-46.

Ang, S., \& Inkpen, A. C. (2008). Cultural intelligence and offshore outsourcing success: A framework of firm-level intercultural capability. Decision Sciences, 39(3), 337-358.

Apte, U. M., \& Mason, R. O. (1995). Global disaggregation of information-intensive services. Management Science, 41(7), 1250-1262.

Ashforth, B. E., \& Mael, F. (1989). Social identity theory and the organization. Academy of Management Review, 14(1), 20-39.

Asmussen, C. G., Larsen, M. M., \& Pedersen, T. (2016). Organizational adaptation in offshoring: The relative performance of home-and host-based learning strategies. Organization Science, 27(4), 911-928.

Beugre, C. D., \& Acar, W. (2008). Offshoring and cross-border interorganizational relationships: A justice model. Decision Sciences, 39(3), 445-468.

Bhalla, A., Sodhi, M. S., \& Son, B.-G. (2008). Is more IT offshoring better? An exploratory study of Western companies offshoring to South East Asia. Journal of Operations Management, 26(2), 322-335.

Boehe, D. M. (2010). Captive offshoring of new product development in Brazil. Management International Review, 50(6), 747-773.

Bunyaratavej, K., Hahn, E. D., \& Doh, J. P. (2008). Multinational investment and host country development: Location efficiencies for services offshoring. Journal of World Business, 43(2), 227-242.

Carmel, E., \& Agarwal, R. (2002). The maturation of offshore sourcing of information technology work. MIS Quarterly Executive, 1(2), 65-78.

Clampit, J., Kedia, B., Fabian, F., \& Gaffney, N. (2015). Offshoring satisfaction: The role of partnership credibility and cultural complementarity. Journal of World Business, 50(1), 79-93.

Contractor, F., Kumar, V., Kundu, S., \& Pedersen, T. (2010). Reconceptualizing the organization in a world of outsourcing and offshoring: The organizational and geographical relocation of high-value company functions. Journal of Management Studies, 47, 1417-1433.

Daft, R. L., \& Lengel, R. H. (1986). Organizational information requirements, media richness and structural design. Management Science, 32(5), 554-571.

Doh, J. P. (2005). Offshore outsourcing: Implications for international business and strategic management theory and practice. Journal of Management Studies, 42(3), 695-704.

Doh, J. P., Bunyaratavej, K., \& Hahn, E. D. (2009). Separable but not equal: The location determinants of discrete services offshoring activities. Journal of International Business Studies, 40(6), 926-943.

Edmondson, A. C., \& McManus, S. E. (2007). Methodological fit in organizational field research. Academy of Management Review, 32(4), 1155-1179.

Eisenhardt, K. M. (1989). Agency theory: An assessment and review. Academy of Management Review, 14, 57-74.

Eisenhardt, K. M., \& Graebner, M. E. (2007). Theory building from cases: Opportunities and challenges. Academy of Management Journal, 50(1), 25-32.

Ellram, L. M., Tate, W. L., \& Billington, C. (2008). Offshore outsourcing of professional services: A transaction cost economics perspective. Journal of Operations Management, 26(2), 148-163.

Feeny, D., \& Willcocks, L. (1998). Core IS capabilities for exploiting information technology. Sloan Management Review, 39(3), 9-21.

Gerbl, M., McIvor, R., Loane, S., \& Humphreys, P. (2015). A multi-theory approach to understanding the business process outsourcing decision. Journal of World Business, 50(3), 505-518.

Gioia, D. A., Corley, K. G., \& Hamilton, A. L. (2013). Seeking qualitative rigor in inductive research: Notes on the Gioia methodology. Organizational research methods, 16(1), 15-31.

Glaser, B. G., \& Strauss, A. L. (1967). The discovery of grounded theory: Strategies for qualitative research. London: Aldine Publishing Company.

Gopal, A., \& Koka, B. R. (2010). The role of contracts on quality and returns to quality in offshore software development outsourcing. Decision Sciences, 41, 491-516.

Gopal, A., Konduru, S., Krishnan, M. S., \& Mukhopadhyay, T. (2003). Contracts in offshore software development: An empirical analysis. Management Science, 49(12), 1671-1689.

Gopal, A., \& Sivaramakrishnan, K. (2008). Research note-On vendor preferences for contract types in offshore software projects: The case of fixed price vs. time and materials contracts. Information Systems Research, 19(2), 202-220.

Hahn, E. D., Bunyaratavej, K., \& Doh, J. P. (2011). Impacts of risk and service type on nearshore and offshore investment location decisions. Management International Review, 51(3), 357-380. 
Hahn, E. D., Doh, J. P., \& Bunyaratavej, K. (2009). The evolution of risk in information systems offshoring: The impact of home country risk, firm learning, and competitive dynamics. MIS Quarterly, 33(3), 597-616.

Haleem, F., Farooq, S., Wæhrens, B. V., \& Boer, H. (2018). Offshoring experience and performance: The role of realized drivers and risk management. Supply Chain Management: An International Journal, 23(6), 531-544.

Handley, S. M., \& Benton, W. C., Jr. (2013). The influence of task-and location-specific complexity on the control and coordination costs in global outsourcing relationships. Journal of Operations Management, 31(3), 109-128.

Hutzschenreuter, T., Lewin, A. Y., \& Dresel, S. (2011). Time to success in offshoring business processes. Management International Review, 51(1), 65-92.

Jain, N. K., Kundu, S. K., \& Niederman, F. A. (2008). Offshoring propensity in information technology services: A firm and country level analysis. Management International Review, 48(4), 447-461.

Jensen, P. D. Ø. (2009). A learning perspective on the offshoring of advanced services. Journal of International Management, 15(2), 181-193.

Jensen, K. W., Håkonsson, D. D., Burton, R. M., \& Obel, B. (2009). Embedding virtuality into organization design theory: Virtuality and its information processing consequences. New approaches to organization design (pp. 99-119). Boston: Springer.

Jensen, P. D. Ø., \& Pedersen, T. (2011). The economic geography of offshoring: The fit between activities and local context. Journal of Management Studies, 48(2), 352-372.

Jha, S. K., Dhanaraj, C., \& Krishnan, R. T. (2018). From arbitrage to global innovation: Evolution of multinational R\&D in emerging markets. Management International Review, 58(4), 633-661.

Kedia, B. L., \& Mukherjee, D. (2009). Understanding offshoring: A research framework based on disintegration, location and externalization advantages. Journal of World Business, 44(3), 250-261.

King, W. R., \& Torkzadeh, G. (2008). Information systems offshoring: Research status and issues. MIS Quarterly, 32(2), 205-225.

Kinkel, S. (2014). Future and impact of backshoring-Some conclusions from 15 years of research on German practices. Journal of Purchasing and Supply Management, 20(1), 63-65.

Lahiri, S., Kedia, B. L., \& Mukherjee, D. (2012). The impact of management capability on the resourceperformance linkage: Examining Indian outsourcing providers. Journal of World Business, 47(1), 145-155.

Larsen, M. M., Manning, S., \& Pedersen, T. (2013). Uncovering the hidden costs of offshoring: The interplay of complexity, organizational design, and experience. Strategic Management Journal, 34(5), 533-552.

Lehrer, M., \& Asakawa, K. (2003). Offshore knowledge incubation: The "third path" for embedding R\&D labs in foreign systems of innovation. Journal of World Business, 37(4), 297-306.

Levina, N., \& Vaast, E. (2008). Innovating or doing as told? Status differences and overlapping boundaries in offshore collaboration. MIS Quarterly, 32(2), 307-332.

Levitt, B., \& March, J. G. (1988). Organizational learning. Annual Review of Sociology, 14, 319-340.

Levy, D. (2005). Offshoring in the new global political economy. Journal of Management Studies, 42(3), 685-693.

Lewin, A. Y., Massini, S., \& Peeters, C. (2009). Why are companies offshoring innovation? The emerging global race for talent. Journal of International Business Studies, 40(6), 901-925.

Lewin, A. Y., \& Peeters, C. (2006). Offshoring work: Business hype or the onset of fundamental transformation? Long Range Planning, 39(3), 221-239.

Lieberman, J. I. (2004). Offshore outsourcing and America's competitive edge: Losing out in the high technology R\&D and services sectors (U.S. Senate Report). Washington, DC: U.S. Senate.

Liesch, P. W., Buckley, P. J., Simonin, B. L., \& Knight, G. (2012). Organizing the modern firm in the worldwide market for market transactions. Management International Review, 52(1), 3-21.

Lin, N., Tan, H., \& Chen, S. (2017). Global offshoring portfolio diversity and performance implications. International Journal of Physical Distribution \& Logistics Management, 47(2-3), 114-136.

Liu, R., Feils, D. J., \& Scholnick, B. (2011). Why are different services outsourced to different countries? Journal of International Business Studies, 42(4), 558-571.

Mael, F., \& Ashforth, B. E. (1992). Alumni and their alma mater: A partial test of the reformulated model of organizational identification. Journal of Organizational Behavior, 13(2), 103-123.

Manning, S. (2013). New Silicon Valleys or a new species? Commoditization of knowledge work and the rise of knowledge services clusters. Research Policy, 42(2), 379-390. 
Manning, S. (2014). Mitigate, tolerate or relocate? Offshoring challenges, strategic imperatives and resource constraints. Journal of World Business, 49(4), 522-535.

Manning, S., Massini, S., \& Lewin, A. Y. (2008). A dynamic perspective on next-generation offshoring: The global sourcing of science and engineering talent. Academy of Management Perspectives, 22(3), 35-54.

Martinez-Noya, A., Garcia-Canal, E., \& Guillen, M. F. (2012). International R\&D service outsourcing by technology-intensive firms: whether and where? Journal of International Management, 18(1), 18-37.

McCutcheon, D. M., \& Meredith, J. R. (1993). Conducting case study research in operations management. Journal of Operations Management, 11(3), 239-256.

Metters, R., \& Verma, R. (2008). History of offshoring knowledge services. Journal of Operations Management, 26(2), 141-147.

Mihalache, O. R., Jansen, J. J. J. P., Van den Bosch, F. A. J., \& Volberda, H. W. (2012). Offshoring and organization innovation: The moderating role of top management team attributes. Strategic Management Journal, 33(13), 1480-1498.

Mihalache, M., \& Mihalache, O. R. (2016). A decisional framework of offshoring: Integrating insights from 25 years of research to provide direction for future. Decision Sciences, 47(6), 1103-1149.

Mukherjee, D., Gaur, A. S., \& Datta, A. (2013). Creating value through offshore outsourcing: An integrative framework. Journal of International Management, 19(4), 377-389.

Mukherjee, D., Lahiri, S., Ash, S. R., \& Gaur, A. S. (2017). Search motives, local embeddedness, and knowledge outcomes in offshoring. Journal of Business Research, 103, 365-375.

Musteen, M., Ahsan, M., \& Park, T. (2017). SME's, intellectual capital, and offshoring of service activities: An empirical investigation. Management International Review, 57(4), 603-630.

Nieto, M. J., \& Rodríguez, A. (2011). Offshoring of R\&D: Looking abroad to improve innovation performance. Journal of International Business Studies, 42(3), 345-361.

Nunn, N., \& Trefler, D. (2013). Incomplete contracts and the boundaries of the multinational firm. Journal of Economic Behavior \& Organization, 94, 330-344.

Olsson, H. H., Conchuir, E. O., Agerfalk, P. J., \& Fitzgerald, B. (2008). Two-stage offshoring: An investigation of the Irish bridge. MIS Quarterly, 32(2), 257-279.

Parida, V., Wincent, J., \& Kohtamäki, M. (2013). Offshoring and improvisational learning: Empirical insights into developing global R\&D capabilities. Industry and Innovation, 20(6), 544-562.

Pascual-Ezama, D., Fosgaard, T. R., Cardenas, J. C., Kujal, P., Veszteg, R., de Liaño, B. G. G., et al. (2015). Context-dependent cheating: Experimental evidence from 16 countries. Journal of Economic Behavior \& Organization, 116, 379-386.

Pisani, N., \& Ricart, J. E. (2016). Offshoring of services: A review of the literature and organizing framework. Management International Review, 56(3), 385-424.

Pisani, N., \& Ricart, J. E. (2018). Offshoring innovation to emerging countries: The effects of IP protection and cultural differences on firms' decision to augment versus exploit home-base-knowledge. Management International Review, 58(6), 871-909.

Rai, A., Maruping, L. M., \& Venkatesh, V. (2009). Offshore information systems project success: The role of social embeddedness and cultural characteristics. MIS Quarterly, 33(3), 617-641.

Ramasubbu, N., Mithas, S., Krishnan, M. S., \& Kemerer, C. F. (2008). Work dispersion, process-based learning, and offshore software development performance. MIS quarterly, 32(2), 437-458.

Ravichandran, R., \& Ahmed, Nu. (1993). Offshore systems-development. Information \& Management, 24(1), 33-40.

Rosenbusch, N., Gusenbauer, M., Hatak, I., Fink, M., \& Meyer, K. E. (2019). Innovation offshoring, institutional context and innovation performance: A meta-analysis. Journal of Management Studies, 56(1), 203-233.

Srikanth, K., \& Puranam, P. (2011). Integrating distributed work: Comparing task design, communication, and tacit coordination mechanisms. Strategic Management Journal, 32(8), 849-975.

Steinberg, P. J., Procher, V. D., \& Urbig, D. (2017). Too much or too little of R\&D offshoring: The impact of captive offshoring and contract offshoring on innovation performance. Research Policy, 46(10), 1810-1823.

Stringfellow, A., Teagarden, M. B., \& Nie, W. (2008). Invisible costs in offshoring services work. Journal of Operations Management, 26(2), 164-179.

Thakur-Wernz, P., \& Bruyaka, O. (2017). Co-evolutionary perspective on sourcing portfolios: Examining sourcing choices for clinical trials of bio-pharmaceutical firms. Management International Review, 57(6), 909-946. 
Tjosvold, D., Tang, M. M., \& West, M. (2004). Reflexivity for team innovation in China: The contribution of goal interdependence. Group \& Organization Management, 29(5), 540-559.

Uzzi, B. (1997). Social structure and competition in interfirm networks: The paradox of embeddedness. Administrative Science Quarterly, 42(1), 35-67.

Van de Ven, A. H. (2007). Engaged scholarship: A guide for organizational and social research. Oxford: Oxford University Press.

Westner, M., \& Strahringer, S. (2010). Determinants of success in IS offshoring projects: Results from an empirical study of German companies. Information \& Management, 47(5-6), 291-299.

Whitaker, J., Mithas, S., \& Krishnan, M. S. (2010). Organizational learning and capabilities for onshore and offshore business process outsourcing. Journal of Management Information Systems, 27(3), 11-42.

Yin, R. K. (1984). Case study research: Designs and methods. London: Sage Publications.

Youngdahl, W., Ramaswamy, K., \& Verma, R. (2008). Exploring new research frontiers in offshoring knowledge and service processes. Journal of Operations Management, 26(2), 135-140.

Publisher's Note Springer Nature remains neutral with regard to jurisdictional claims in published maps and institutional affiliations. 